\title{
USO DO PLANEJAMENTO ESTRATÉGICO SITUACIONAL PARA IDENTIFICAÇÃO DAS NECESSIDADES DE SAÚDE DE UMA POPULAÇÃO ADSCRITA
}

\author{
Nubya Sete Anzolin \\ Graduanda de Enfermagem da Faculdade de Enfermagem da Unicamp. \\ nubya anzolin@hotmail.com
}

INTRODUÇÃO: Atualmente, para organização da demanda espontânea na Atenção Primária à Saúde alguns municípios tem desenvolvido um novo modelo assistencial, o Acesso Avançado (AV), que busca o atendimento imediato à população, sem a presença de agenda física para diagnósticos que não necessitem o acompanhamento programático, por meio de consultas no mesmo dia ou em até uma semana. O Centro de Saúde (CS) Village, localizado no município de Campinas, em uma área predominantemente rural, iniciou o processo de mudança devido a equipe diagnosticar que $o$ atendimento por acolhimento e consultas agendadas não supriam a demanda do território. OBJETIVO: Reconhecer necessidades de saúde da população adscrita do CS Village, para desenvolvimento de ações a serem planejadas pela equipe de saúde. MÉTODO: Relato de experiência baseado no Planejamento Estratégico Situacional (PES) com seus quatro momentos: explicativo, normativo, estratégico e tático-operacional. Desenvolvido pelos graduandos de enfermagem do $2^{\circ}$ ano da FEnf/Unicamp, por meio de: levantamento e análise de dados da população do CS Village dos sistemas de informação (SIM, SINAN, SINASC e IBGE); coleta de dados físicos/manuais arquivados na Unidade do SIS Pré-Natal, SV2, Puericultura e Pacientes Programáticos. Os dados analisados foram compartilhados com a equipe em dois momentos. RESULTADOS: Com este método, obtemos: conhecimento do perfil demográfico, sendo a maioria de jovens/adultos entre 20-65 anos. A maioria das gestantes estavam na faixa etária de 20-34 anos. Sobre os pacientes programáticos, a maioria era hipertensos com médio risco e diabéticos que eram classificados como alto risco. Principais arboviroses identificadas em 2017 foram: Dengue, Febre Maculosa e Leptospirose. CONCLUSÕES: A intervenção proposta permitiu à equipe de saúde do CS Village o reconhecimento da população e suas necessidades de saúde. Desta forma, a divisão de vagas foi feita conforme a quantidade de 
usuários e suas queixas, com melhor distribuição do agendamento e consolidação do Acesso Avançado, pois percebeu-se como o processo de trabalho existente na localidade estava estruturado sem as interligações necessárias entre as categorias atuantes, mostrou como a equipe deve se organizar e atuar conforme as necessidades existentes e as características impostas pelo AV.

Palavras-chave: Planejamento estratégico. Atenção primária à saúde. Acesso aos serviços de saúde. 